\title{
Massive open online courses: The new vector in classical university education
}

\author{
Galina Mozhaeva ${ }^{\text {la }}$ \\ ${ }^{1}$ Tomsk State University, Tomsk, 634050, Russian Federation
}

\begin{abstract}
The influence of Massive Open Online Course (MOOC) on classical university education is investigated. Opportunities and prospects of development of $\mathrm{MOOC}$ at classical universities, requirements to development and implementation of qualitative MOOC-projects, conditions and mechanisms of integration of MOOC into professional education are studied. Work is performed on the basis of the analysis of experience of the world MOOC-platforms and the Russian universities. The new vector in development of classical university under the influence of MOOC is considered on the example of National Research Tomsk State University (http://www.lektorium.tv/mooc). Questioning more than 5000 participants of MOOC-projects was carried out, motivators of learning are revealed, and marketing potential of MOOC and possibility of analytical work on an assessment of the contingent, quality of education and efficiency of the applied technologies are analyzed. The quantitative analysis of basic data is made; results of the analysis are described and presented in the graphic form.
\end{abstract}

Keywords: massive open online course; MOOC; e-learning; classical university

\section{Introduction}

The wide circulation of Massive Open Online Courses (further-MOOC, pl. - MOOCs) which the cornerstone idea of mass and public education is, inevitably conducts to formation of a new educational paradigm with the maximum use online of technologies and to creation of the uniform transnational informational and educational environment, [1].

MOOCs have wide geography: America, Germany, Great Britain, India, China... USA are the leader and have the most large number of MOOC-platforms (more than 15) and number of the students who are trained for them (Coursera, 2015; "The market of online education", 2014).

\footnotetext{
${ }^{a}$ Corresponding author: mozhaeva@ido.tsu.ru
} 
Participation in MOOC-projects of the leading world universities (MIT, Stanford, etc.) gives the importance and reliability to the MOOC-projects.

Russia joined to technological race also, having started a number of educational projects in 2013-2014. It is necessary to distinguish from them the academic educational project Lektorium (http://www.lektorium.tv/mooc), the project Universarium (universarium.org) and some other. Along with it some Russian higher education institutions, including MIPT, HSE and St.Petersburg State University, came to the Coursera platform on which only courses of foreign universities were presented before, [4].

Prompt emergence of MOOC-projects caused contradictory estimates - from sharp rejection to enthusiastic greetings of MOOK as new educational format which will destroy modern universities and will replace them. Supporters of the optimistical point of view consider online training as the productive and meeting requirements of a modern era mechanism. A number of researches is connected with forecasts about the prospects of development of MOOK-pedagogics constructed on analytical research of already available results of training, [5]. Pessimistic moods are expressed mistrust to this way of training in general, [6] and note an undevelopment of the general pedagogical principles for mass introduction of this technology, [7].

Especially heated debates round MOOC take place at the classical universities which are historically focused on fundamental nature and traditional learning in campus.

In this work an attempt of judgment of influence of MOOC on classical university education and the directions of transformation of classical university education under the influence of MOOC-projects is made. It is necessary to study opportunities and prospects of development of MOOC at classical universities, requirements to development and implementation of qualitative MOOC-projects, conditions and mechanisms of integration of MOOC into professional education.

\section{Methods and instruments}

The methods are used in research: questioning, focus-group, statistical data processing and comparative analysis of results. Google Forms were used for data collection and their preprocessing.

Questioning more than 5000 participants of the TSU MOOC-projects was carried out during research. It allowed to reveal motivators of learning, to analyze the marketing potential of MOOC and possibility of analytical work on an assessment of the contingent, quality of education and efficiency of the applied technologies. The quantitative analysis of basic data is made.

Work is performed on the basis of the analysis of experience of the largest world MOOC-platforms and the Russian universities developing a national online platform. The new vector in development of classical university under the influence of MOOC is considered on the example of National Research Tomsk State University (further - TSU). TSU is the oldest classical University in Siberia. It was founded in 1878, and today it is one of 15 leading Universities of Russia. TSU became the first Russian University on the European MOOC-platform Iversity and the fourth - on the American Coursera.

\section{Results}

\subsection{Main key features and pedagogical tools of MOOCs}

The key features of MOOC connected with realization of the principles of a continuity and individualization of education. 
Firstly, it is massive involvement which consists in limitlessness of number of course listeners, on the one hand, and in wide audience orientation, on the other hand. Otherwise speaking, the aim of the course is "to talk about something difficult in easy way".

Secondly, it is openness which gives an opportunity to gain knowledge for free - to learn in a course.

Thirdly, it is online what means that it is possible to receive distance education at a time and in a place which are convenient to the listener.

Fourthly, it is not a fragment of learning material; it is exactly the course which content contemplates structured learning and controlling materials.

The fifth, it is an opportunity to receive a certificate in case of a successful completion of the course.

Also the main pedagogical tools forming the MOOC technology should be noted.

The first and, perhaps, the main, tool are short videos which capture the basic course content.

Check forms of work are the second tool: tests, short free answers, tasks with formula derivation and programming.

The third tool is free communication of participants of educational process in forums, by peer-to-peer learning, crowdsourcing projects (as wiki), team work on projects.

Therefore, new pedagogical technologies and tools allow to create an essentially new cover for learning material satisfying the tendencies of time. This technology allows "to pack" knowledge into a form, available to understanding.

\subsection{What interferes with development of mass online education?}

The number of factors interfering development of mass online of university education are considered:

- virtual education in the opinion of employers strongly loses to traditional forms of education;

- low level of motivation to training of most of students and inability to study independently that leads to low interest of the students (2-14\%) finishing training;

- distinctions in education systems of various countries;

- language barriers as the majority of MOOC are developed in English;

- lack of the mechanism of inclusion of MOOC in programs of the higher education.

However and this problem is solved. The movement in the direction of offset of results of training on online courses is observed in the USA and in Europe today. So, the European Commission decided to support the VMPass project (Recognition of VIRTUAL MOBILITY and OER-LEARNING Through a Learning Passport) that is an attempt to equate online occupations to real, with possibility of using of results of MOOCcertification in programs of formal training, including university (VMPass, n.d.).

The Ministry of Education and Science of the Russian Federation also discusses a question that the Russian higher education institutions will be able to reckon open online courses on the leading world platforms to students since September, 2015. Of course, high requirements to quality of courses and to procedures of an assessment of results of training have to be developed.

\subsection{From informal to formal education: experience of Tomsk State University}

Experience of inclusion of MOOC in the main educational programs in foreign higher education institutions is investigated; conditions and mechanisms of integration of MOOC into classical university education on the example of the American and Russian universities are analyzed. 
Widespread introduction of the Open Online Courses conducts to gradual mixing of formal and informal education that is most quicker shown in the sphere of additional education.

The scheme of monetization of MOOK through programs of additional professional education at university as one of the most effective ways of monetization of MOOC for Russia is developed and analyzed. This scheme is approved in TSU on the example of 4 MOOC.

1. "Sketches of Siberia. Tomsk" is directed on studying of Russian as foreign through materials about Siberia, history and cultural heritage of Tomsk.

2. "Genius. Talent. Golden mediocrity" is directed on studying of psychology of the personality.

3. "Russian as an instrument of successful communication"

4. "Amazing World of Geography"

By the end of 2015 their quantity will reach 15.

At the moment National Research Tomsk State University is actively carrying out a number of actions for creation of Massive Open Online Courses.

The implementation of this project includes the following stages: development, direction, video production, publication and technical maintenance of courses. By the implementation of the project there is expected achievement of the following purposes:

- improvement of quality of University educational programs by means of feedback from a wide audience from different regions of Russia and other countries;

- increase of recognition of the University brand;

- drawing of attention to the University of a great number of Internet users including potential applicants to Bachelor's or Master's degree programs;

- analysis of efficiency of on-line mechanisms use for drawing of user's attention to the University educational content.

\subsection{Why mass online projects gain fast development?}

The analysis of rapid development of MOOC in the world allows to mark out the main advantages of MOOC:

- positioning of the universities opening their virtual doors for the mass student;

- increase of recognition of a brand of university and its rating, including at the international level;

- use of MOOC as effective marketing tool for attraction of talented and gifted youth for training at university;

- increase of quality of educational programs due to receiving feedback from wide audience from different regions of the world;

- analysis of efficiency of use of on-line mechanisms for attracting attention of users to educational content of university;

- assessment of progress in training for trainees;

- assurance of availability of education to citizens with limited opportunities of health.

Education becomes really open and mass, not demanding special financial expenses and allowing to realize virtual mobility.

\subsection{Learner profile}

The analysis of target audience of TSU's MOOCs showed that the vast majority of participants of a courses already has education and a profession. There are mainly young people aged from 17 till 35 years (55\% of participants of a course) which are having $(75 \%)$ 
or are getting higher education (18th \%).

As a rule, training is not their main occupation. Participation in an online course is absolutely voluntary that often results in absence of obligations and motivation to continue training. From here there is quite big percent of the students who stopped training and did not reach the end of a course.

There are about 13\% people who registered and finished training, and about $5 \%$ ended a course with honors. It is an indicator on the Russian MOOC. In the USA from 2 to $14 \%$ of listeners finishes training on MOOC.

The first TSU MOOC-projects were started on the Russian Lektorium platform in Russian. Despite it, the geography of listeners of a course was extensive: 42 countries of the world, including Great Britain, Germany, Netherlands, Hungary, Serbia, Poland, China, Bulgaria, Czech Republic, Vietnam, India, Taiwan, Kazakhstan, Mongolia, Uzbekistan, Ukraine, Russia, etc. The greatest number of listeners represented Russia, Ukraine, Kazakhstan, Bulgaria, Belarus, Moldova, Latvia, Vietnam and Netherlands.

The analysis of age structure of listeners of MOOC TSU is shown in Fig.1:

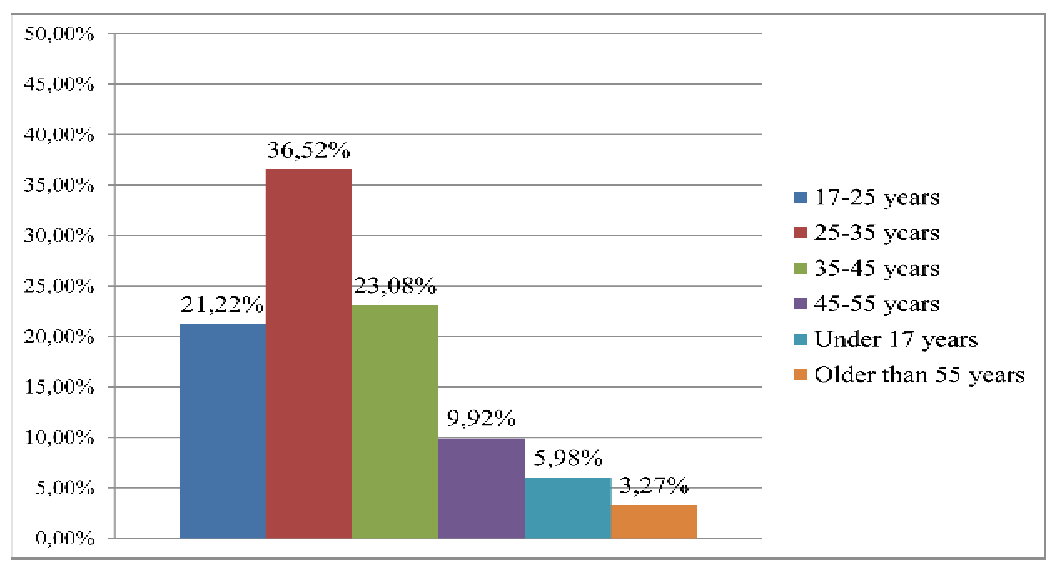

Fig. 1. Age ranges of TSU's MOOCs learners.

Distinctions of listeners on education level are presented in Fig.2.

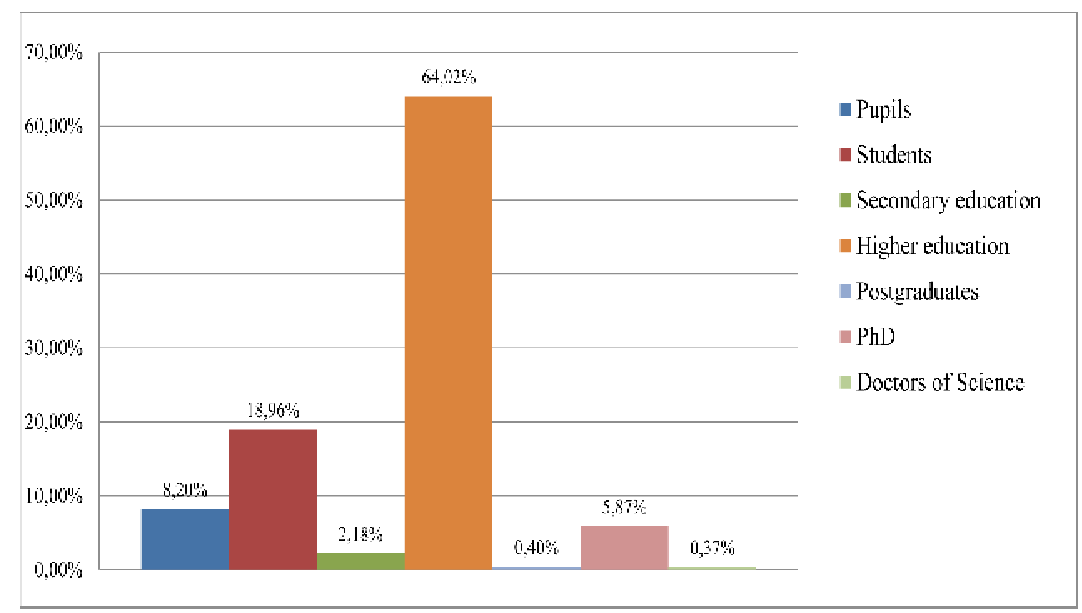

Fig.2. Distinctions of listeners on education level.

The great range (subjects and levels) of MOOCs suggests that a typical profile of a 
MOOC learner can only be indicative as each courses' characteristics will impact on the elements which make up the profile.

As an indication, however, we can draw the following profile from the TSU's MOOCs:

Table 1. Profile from the TSU's MOOCs.

\begin{tabular}{ll}
\hline Gender & Both approximately equally \\
\hline Age & Between 17-45 years old \\
\hline Country & $\begin{array}{l}\text { 42 countries - Russia, Ukraine, Republic of Kazakhstan, Bulgaria, Republic of } \\
\text { Belarus, Republic of Moldova, Latvia, Vietnam, Netherlands, etc. }\end{array}$ \\
\hline Education & Higher education (71\%) or students (19\%) \\
\hline Status & $\begin{array}{l}\text { Generally working person (full or part-time). Online training - not the main } \\
\text { occupation. }\end{array}$ \\
\hline
\end{tabular}

\section{Conclusion}

Results of work allow drawing a conclusion on the high potential of MOOC as resources of continuous university education. The labor market which doesn't recognize results of MOOC-learning yet becomes the main limiter on the way of development of MOOC. Use of MOOC in additional education of the adults is considered by the author as the most perspective direction of development of MOOC in Russia soon.

On the basis of the conducted research the question of need of development of the pedagogical principles for mass introduction of MOOC in classical universities is raised.

Research shows that the MOOC format reflects the changes occurring in an education system and new tendencies in development of modern society as societies of knowledge.

Projects on development online of courses will allow classical university, on the one hand, to join in system of global education and to work with students of the whole world, on the other hand, courses will act as the effective marketing tool for attraction of talented and gifted youth for training at university.

\section{Acknowledgements}

This research is supported by Tomsk State University Competitiveness Improvement Program.

\section{References}

1. Moore M. G., Independent Learning, MOOCs, and the Open Badges Infrastructure. American Journal of Distance Education, Vol. 27, Issue 2, 75-76. Retrieved March 13, 2015, from http://www.tandfonline.com/doi/full/10.1080/08923647.2013.786935\#.VFodSvmsV4w., (2013).

2. Coursera., Retrieved March 15, 2015, from https://www.coursera.org/, (2015)..

3. The market of online education in Russia and the world: segment of mass online courses, Retrieved March 15, 2015, from http://json.tv/ict_telecom_analytics_view/rynok-onlayn-obrazovaniya-v-rossii-i-miresegment-massovyh-onlayn-kursov-20141209065340, (2014).

4. The exhaustive review of the Russian market of MOOC is issued (2014). Retrieved March 15, 2015, from http://www.edutainme.ru/post/vypushchen-ischerpyvayushchiyobzor-rossiyskogo-rynka-mooc/, (2015). 
5. Maureen Ebben, Julien S. Murphy, Unpacking MOOC scholarly discourse: a review of nascent MOOC scholarship. Learning, Media and Technology, 1-18. Retrieved March 15, 2015, from http://dx.doi.org/10.1080/17439884.2013.878352. (2014).

6. Jon Baggaley, MOOC rampant. Distance Education, Vol. 34, No. 3, 368-378. Retrieved March 15, 2015, from http://dx.doi.org/10.1080/01587919.2013.835768. (2013).

7. Marc Clarà, Elena Barberà. Learning online: massive open online courses (MOOCs), connectivism, and cultural psychology. Distance Education, Vol. 34, No. 1, 129-136. Retrieved March 15, 2015, from http://dx.doi.org/10.1080/01587919.2013.770428. (2013).

8. VMPass. (n.d.). Retrieved March 15, 2015, from http://vmpass.eu/. 